\title{
El acceso de la juventud al espacio público en Manresa. Una aproximación desde las geografías feministas de la interseccionalidad
}

\author{
Maria Rodó de Zárate \\ Universitat Autònoma de Barcelona \\ maria.rodo@gmail.com
}

El acceso de la juventud al espacio público en Manresa. Una aproximación desde las geografías feministas de la interseccionalidad (Resumen).

La juventud es en sí misma un colectivo heterogéneo y está atravesada por diferentes identidades de género, etnicidad, orientación sexual, clase y edad. Estas identidades condicionan su forma de vivir la ciudad, restringiendo o permitiendo su acceso a ella. En este artículo analizo los usos y las experiencias de la gente joven en Manresa desde una perspectiva feminista interseccional, es decir, teniendo en cuenta sus múltiples identidades como mutuamente constituidas y vividas de forma simultánea. A través de diversas metodologías cualitativas analizo las experiencias de treinta y un jóvenes con el objetivo de ver cómo están en la calle, poniendo especial énfasis en su capacidad de negociación espacial. El miedo, el control por parte de la comunidad y la heteronormatividad aparecen como los factores más determinantes del acceso al espacio público, a la vez que se muestra la necesidad de analizar las formas de subordinación en el espacio privado para comprender las dinámicas espaciales en la esfera pública.

Palabras clave: interseccionalidad, juventud, espacio público, género, feminismo.

Youth access to Manresa's public space: An intersectional feminist geographies approach (Abstract).

Youth is an heterogeneous group, crossed by different identities such as gender, ethnicity, sexual orientation class and age. These identities condition the way they live the city, limiting or allowing their access to it. In this paper I analyze the uses and experiences of young people in Manresa from a feminist intersectional perspective, it is, taking into account their multiple identities as mutually constituted and simoultaneously experienced. Through diverse qualitative methodologies I examine the experiences of thirty one young people with the aim to explore how they are in the street, focusing on their abilities to negotiate spatial conditioning. Fear, social control by their own community and heteronormativity appeared as the most determinant factors for their access to public space, showing at the same time the necessity of analyzing the forms of subordination in private space to understand the spatial dynamics in the public sphere.

Keywords: intersectionality, youth, public space, gender, feminism. 
La juventud ha sido muy poco estudiada en las espacialidades urbanas y el análisis de las ciudades, a pesar de ser uno de los mayores grupos demográficos a nivel global. Skelton y Gough ${ }^{1}$, en la introducción del monográfico sobre jóvenes de la revista Urban Studies muestran la ausencia de la gente joven en los estudios académicos y argumentan que el hecho de "tener en cuenta a la juventud en la ciudad permite la posibilidad establecer nuevas aproximaciones conceptuales que pueden ser muy útiles para capturar las complejidades de las ciudades contemporáneas"2. Pero la necesidad de tener en cuenta a la juventud en los estudios urbanos no es solo una cuestión de ausencias y presencias. La gente joven no solo está en las ciudades sino que son agentes en la producción de las ciudades y a la vez sus vidas son moldeadas por las dinámicas urbanas $^{3}$. En el contexto del estado español, la juventud está siendo uno de los grupos que está sufriendo la crisis económica de forma más dura. Según la Encuesta de Población Activa, la tasa de paro entre personas de 16 a 25 años ronda el 55\% en 2013. La falta de empleo en estas edades repercute no solo en la autonomía económica sino también en las posibilidades de emancipación y de creación de proyectos propios. En medio de esta situación, ¿cómo vive la juventud la ciudad? ¿Qué puede aportar el análisis de las espacialidades de la juventud desde una perspectiva feminista al estudio de las ciudades?

En el siguiente artículo, pretendo analizar el acceso que tiene la juventud al espacio público en Manresa, una ciudad mediana catalana. En esta investigación, desarrollada en el marco de la tesis doctoral ${ }^{4}$, parto de la heterogeneidad de la juventud para examinar cuáles son sus prácticas desde una perspectiva feminista interseccional. A través de las entrevistas, los mapas de itinerarios y de los Mapas de Relieves de la Experiencia de treinta jóvenes de entre 16 y 29 años ${ }^{5}$ que se sitúan en diversas posiciones de género, sexualidad, etnia y clase social pretendo poner de relieve la diversidad de experiencias y usos del espacio público en una ciudad mediana, demostrando como su acceso al espacio público está restringido según sus diversas identidades. Así, defiendo que el acceso de la gente joven al espacio público no es solo una cuestión de presencias y ausencias sino que la forma cómo se está en la calle es crucial para determinarlo. Alejándome de la comprensión de la justicia espacial como territorialización, sitúo la experiencia en el centro del análisis para ver el malestar o el bienestar que la juventud siente en el espacio público. Con el trabajo empírico realizado, se muestra cómo sus experiencias son consecuencia no solo de su edad sino de la constitución de ésta en relación a otras estructuras de poder, poniendo de manifiesto que la interseccionalidad es una herramienta útil y necesaria para el estudio de las relaciones entre los espacios y las relaciones sociales. A la vez, se pone énfasis en cómo la juventud es capaz de crear estrategias y lugares que les permiten estar bien, centrando la atención en sus estrategias cotidianas de gestión de sus identidades y de los espacios. Por otra parte, los datos empíricos muestran como el acceso al espacio público depende de la forma en la que se está en el espacio privado, problematizando la separación entre público y privado y

\footnotetext{
${ }^{1}$ Skelton y Gough, 2013

${ }^{2}$ Skelton y Gough, 2013, p. 456

${ }^{3}$ Skelton y Gough, 2013

${ }^{4}$ Investigación llevada a cabo dentro del proyecto 'Plan Nacional de I+D+I 2008-2011' [2009; CSO200910913], y gracias a la beca FPI del Ministerio español de Ciencia e Innovación.

${ }^{5}$ Partiendo de la dificultad de definir en términos de edad quién es joven, he tomado la definición que normalmente se usa en los estudios llevados a cabo en Cataluña y la que las administraciones usan para realizar políticas públicas sobre juventud. Ver Pla Nacional de Joventut 2010-20.
} 
mostrando como el derecho a la ciudad pasa irremediablemente por la no discriminación en el espacio privado.

\section{Geografías Feministas de la Interseccionalidad}

El concepto de interseccionalidad fue introducido a finales de los años 80 por Kimberlé Crenshaw ${ }^{6}$ como una forma de describir las interconexiones existentes entre ' $\mathrm{raza}^{7}{ }^{7} \mathrm{y}$ género. La autora mostraba como ni los estudios sobre género ni los referentes a la 'raza' podían dar cuenta de la opresión de las mujeres negras en Estados Unidos, ya que su experiencia no era la suma de esas opresiones sino una intersección concreta que conllevaba discriminaciones y violencias específicas. Sus contribuciones, enmarcadas en el Feminismo Negro norte-americano, seguían el intento de cuestionar el sujeto del feminismo, que se había construido sobre la idea de una mujer blanca, heterosexual y de clase media. La idea de que la experiencia de opresión de las mujeres no podía ser explicada por un sólo marco explicativo como el género ya había sido desarrollada por los movimientos sociales en el estado español antes de la introducción del término ${ }^{8}$, pero el desarrollo teórico del concepto de interseccionalidad a nivel internacional permitió la profundización teórica en relación a las interconexiones de las estructuras de poder como el género, la etnicidad, la sexualidad, la clase social, la edad o la discapacidad.

El hecho de entender que todas las personas estamos atravesadas por estas estructuras de forma simultánea, ya sea en posiciones de privilegio u opresión, ha sido crucial para el feminismo y el estudio de las relaciones de poder. En la geografía feminista este concepto sólo se ha introducido muy recientemente ${ }^{9}$, a pesar de las importantes implicaciones que la interseccionalidad tiene para el análisis de la producción del espacio y el poder. El mismo nombre de interseccionalidad se remite a una metáfora espacial y las autoras se han referido a rotondas, cruces y otros elementos con una gran connotación geográfica para describir el hecho de que diferentes estructuras de poder nos atraviesan al mismo tiempo y en direcciones diferentes, causando opresiones específicas.

En los estudios sobre juventud, a nivel internacional en geografía, se ha mostrado la heterogeneidad existente entre la juventud y la necesidad de estudiar sus múltiples identidades ${ }^{10} \mathrm{y}$ algunas autoras han relacionado las cuestiones referentes a la edad con el género, la clase social o la etnia ${ }^{11}$. Pero el estudio sistemáticamente interseccional no se da en la mayoría de estudios, haciendo que algunas identidades hegemónicas prevalezcan en la investigación sobre estas temáticas.

En general, la literatura sobre jóvenes y espacio público muestra cómo esta relación es compleja y contradictoria. La calle se ve como un lugar dónde la gente joven puede encontrar libertad y dónde construye en gran medida su identidad, lejos de la mirada

\footnotetext{
${ }^{6}$ Crenshaw, 1991

${ }^{7}$ Utilizo el término 'raza' ya que ella usa 'race' en inglés.

${ }^{8}$ véase Platero, 2012

${ }^{9}$ ver Valentine, 2007; McDowell, 2008; Brown; 2011

${ }^{10}$ Evans, 2006; Hopkins y Pain, 2007

${ }^{11}$ Gough i Franch, 2005; Evans, 2006; Hyams, 2003; Koning, 2009, Ehrkamp, 2008
} 
adulta $^{12}$. Pero este espacio es un lugar construido por personas adultas según sus necesidades e intereses. Este proceso de producción del espacio como espacio adulto es lo que se llama 'adultificación'. Y dada esta hegemonía, la juventud queda excluida de un espacio supervisado por la presencia de personas adultas que lo definen, gobiernan y controlan $^{13}$. Por otro lado, el comportamiento antisocial generalmente se asocia con la juventud, relacionándola con drogas, grafitis o el ruido ${ }^{14}$. Y dado que es vista como una amenaza a la hegemonía adulta ${ }^{15}$, sus actividades son reguladas tanto por la familia como por las autoridades o la policía en forma de regulaciones, normas o prohibiciones que controlan y determinan su acceso al espacio público.

Existen varios artículos en geografía sobre este tipo de regulaciones en cuestiones como el skateboarding ${ }^{16}$, los toques de queda ${ }^{17}$ o los locales de ocio ${ }^{18}$. En el contexto estudiado, a raíz de la llamada 'Ordenança del Civisme de Barcelona', muchas ordenanzas municipales fueron aprobadas, también en Manresa. En ellas se prohíben actividades como comer o beber en la calle, potenciando que estas actividades solo se realicen en bares y terrazas. Se prohíbe jugar, se penaliza la organización de eventos y se sanciona el sentarse en el suelo, por citar algunos ejemplos. Actividades de ocio que la juventud realiza (como los casos de botellón) son considerados 'fuera de lugar' y son sancionadas.

En el contexto catalán, existen trabajos sobre juventud desde la sociología ${ }^{19}$, la antropología $^{20}$ y estudios interdisciplinares sobre juventud ${ }^{21}$. En geografía, existen muy pocos trabajos sobre juventud y espacio público $^{22}$, aunque se encuentran trabajos en el ámbito metropolitano de Barcelona ${ }^{23}$ y algunas publicaciones de la revista Documents d'Anàlisi Geogràfica ${ }^{24}$. Es relevante destacar el monográfico "Geografies de la infància, la joventut i les famílies", como también los artículos sobre espacios públicos urbanos y género ${ }^{25}$ y algunos artículos sobre la interacción de estas dos variables con la infancia o la adolescencia26. Es también destacable la reciente publicación de dos libros: Espacios Públicos, Género y diversidad: geografías para unas ciudades inclusivas, que incluye artículos sobre juventud, y Jóvenes y espacio público. Del estigma a la indignación ${ }^{27}$. Este texto, si bien aborda cuestiones fundamentales sobre este grupo

\footnotetext{
${ }^{12}$ Gough y Franch, 2005; Lieshout y Aarts, 2008

${ }^{13}$ Driskell et altri, 2008

${ }^{14}$ Wooley, 2006

${ }^{15}$ Gough y Franch, 2005; Thomas, 2005

${ }^{16}$ Chiu, 2009; Nolan, 2003; Wooley, 2006

${ }^{17}$ O'Neil, 2002; Collins y Kearns, 2001

18 Travlou et altri, 2008; Thomas, 2005; Chatterton y Hollands, 2002

${ }_{19}$ Ver Papers: Revista de Sociologia, con números monográficos dedicados a temas de juventud, como el volúmen 96, número 1 «Jóvenes e identidad» (2011), el número 90: «Famílies i adolescents» (2008), el número 79: «Materials de Sociologia de la Joventut»(2006) o el número 74: «Evolució social i joventut» (2004).

${ }^{20}$ Ver los estudios etnográficos sobre juventud de Carles Feixa.

${ }^{21}$ Ver Primer Congrés Internacional Joventut $i$ Societat, organizado a través del 'Màster Interuniversitari en Joventut i Societat', 2009.

${ }^{22}$ Rodó-de-Zárate, 2011

${ }^{23}$ Nofre, 2008

${ }^{24}$ Departamento de Geografía de la Universitat Autònoma de Barcelona i Departamento de Geografía de la Universitat de Girona.

${ }^{25}$ Cucurella, 2007; Fernández, 2007; Ortiz, 2004; Serra, 2007

${ }^{26}$ Katz, 2006; Ortiz, 2007; Baylina et al., 2007; Prats et al., 2012; Ortiz et al., 2012

27 Trilla, 2011
} 
social y su relación con el espacio público, no incorpora la perspectiva de género de forma específica (sólo en un capítulo sobre prostitución) ni tampoco transversal.

A pesar de la dificultad de encontrar trabajos sobre juventud y espacio público desde una perspectiva de género, a nivel parcial sí existen otros estudios que ponen de relieve cómo el género concretamente determina la vida cotidiana y las actividades de hombres y mujeres en cuestiones como la movilidad, los tiempos o la seguridad. Como se verá más adelante, las geógrafas feministas han mostrado cómo la ciudad está generizada y excluye a las mujeres del espacio público. El miedo, por ejemplo, es un factor determinante en el uso y la experiencia del espacio público, ya que repercute directamente en el acceso a la ciudad de las chicas jóvenes y su movilidad espacial ${ }^{28}$. En el contexto del estado español y desde otros ámbitos y disciplinas se ha analizado cómo el diseño del espacio público influye en la inseguridad y la violencia contra las mujeres ${ }^{29}$.

En el siguiente apartado voy a detallar la metodología empleada y desarrollada para esta investigación. Con el objetivo de poner de relieve las dinámicas interseccionales de la experiencia de la juventud que condicionan su acceso al espacio público, analizaré los datos obtenidos en el trabajo empírico. Un estudio interseccional de este tipo dificulta la búsqueda de conclusiones aplicables a todo el grupo objeto de estudio. Tomando esta dificultad como una oportunidad, mostraré los resultados de forma que evidencien la misma interseccionalidad y complejidad de la experiencia.

\section{Contexto y metodologías}

El contexto en el que se sitúa esta investigación es en la ciudad de Manresa, una ciudad mediana catalana de cerca de 80.000 habitantes. Manresa se encuentra a unos cincuenta kilómetros de distancia de Barcelona y es la capital de la comarca del Bages. Históricamente fue una importante ciudad industrial pero actualmente su economía se focaliza en el sector de servicios. Durante los años cincuenta y sesenta la ciudad recibió inmigración proveniente del sur del estado español y a partir de los años noventa la mayoría de la inmigración fue de origen suramericano y africano, especialmente del norte de África. El porcentaje de jóvenes en la ciudad (de 15 a 29 años) es de alrededor del $16 \%{ }^{30}$ y un $24,82 \%$ nacieron en un país extranjero. Tomando datos sobre la juventud manresana del 2007, el 53,36\% provenía de África (un 61, 93\% del cual de Marruecos), $19,37 \%$ de América del Sur y el resto, de otros continentes y del resto del Estado ${ }^{31}$.

Se realizaron treinta y una entrevistas a jóvenes de entre 16 y 29 años de Manresa. Para obtener experiencias diversas, se escogieron jóvenes con diferentes identidades de género, sexualidad, etnia y clase social, como también se tuvieron en cuenta cuestiones como el barrio de residencia, el tipo de vivienda, la religión o la situación civil. Se relacionaron estas variables de forma que aparecieran diferentes combinaciones y, por tanto, diferentes experiencias interseccionales. Las entrevistas se seleccionaron, en primer lugar, a través de contactos personales, y después utilizando la técnica 'bola de nieve', por la que unos contactos llevaron a otros.

\footnotetext{
28 Thomas, 2005

${ }^{29}$ Freixanet, 2011

${ }^{30}$ Datos procedentes del Anuari Estadístic de Manresa, 2011. Ajuntament de Manresa.

${ }^{31}$ Datos del Pla Local de Joventut, 2009.
} 
Referente a las características de las personas entrevistadas, se realizaron 23 entrevistas a chicas y 8 a chicos. De las chicas, siete eran lesbianas (de las cuales, cinco catalanas, una marroquí y otra colombiana), diez heterosexuales (de las cuales siete catalanas y tres marroquíes) y tres bisexuales (todas ellas catalanas). Referente a los chicos, dos eran gays (uno catalán y otro colombiano), cuatro heterosexuales (tres catalanes y un marroquí) y un bisexual (catalán). Todas las personas entrevistadas tenían plena movilidad y capacidades físicas e intelectuales. Solamente una de ellas era madre y las formas de convivencia variaron desde la vivienda familiar hasta la okupación de inmuebles.

La diversidad de los lugares de residencia también se tuvo en cuenta, seleccionando personas de barrios diferentes según sus características socioeconómicas, demográficas y urbanísticas, hecho que podía proporcionar una selección de personas con diversas posiciones de clase social. El análisis de clase, en un contexto de crisis económica y con personas mayoritariamente dependientes de sus familias, se convirtió en muy problemático. Con un paro juvenil en Cataluña del $50,12 \%^{32}$, la posición de algunas personas era de extrema vulnerabilidad, sin ingresos familiares y la posibilidad de perder la vivienda, pero su autoidentificación fue (en todos los clases) como de clase media. Actualmente, la disociación de la identidad de clase y los recursos materiales se acentúa en procesos de cambio que se mezclan con el incremento de la precarización de la juventud. Así, a pesar de contar con indicadores (barrio de residencia, formación, etc), la clase se analiza al largo de este trabajo también teniendo en cuenta las restricciones materiales que sufren en su vida cotidiana y cómo afecta su experiencia del espacio público.

Los criterios de selección surgieron en el mismo proceso de investigación y este fue el que guió la selección. No se procuró tanto que la muestra fuera representativa de la ciudad como que las combinaciones identitarias pudieran iluminar la complejidad de las experiencias de la juventud en el espacio público, ya que las identidades minoritarias o marginadas no solo pueden dar información sobre sus propias experiencias sino que suponen una interesante perspectiva desde la que analizar el 'centro' 33 .

Las entrevistas se basaron en el uso y la experiencia del espacio público a través de, primero, preguntas generales sobre su concepto de 'espacio público', sus lugares cotidianos y sus experiencias en ellos. A continuación, las preguntas que se realizaron fueron sobre aspectos concretos de las experiencias en cada espacio mencionado, poniendo especial énfasis en los espacios considerados como públicos. Preguntas como ¿por qué te gusta este lugar?, ¿cómo te gustaría que fuera? o ¿qué crees que hace que te sientas así?, ayudaron a guiar las entrevistas. Por otro lado, y para focalizar la atención en sus identidades, se preguntaron cuestiones como ¿te sentirías igual si fueras un chico? o ¿crees que te pasaría lo mismo si no fueras gay? De esta forma se puso énfasis en la relación entre sus identidades y sus experiencias. Todas las entrevistas fueron gravadas y transcritas. De las treinta y una personas entrevistadas, con un grupo de diez chicas de entre 16 y 21 años pertenecientes a un grupo feminista de la ciudad no se realizaron entrevistas individuales sino que se llevó a cabo una aproximación de Investigación

\footnotetext{
${ }^{32}$ Datos de 2013 referentes al grupo de edad de 15 a 24 años. Pla Local de Joventut, 2013-2016.

${ }^{33}$ hooks, 1984
} 
Acción Participativa en la que se dieron diversos encuentros y debates ${ }^{34}$. En otros casos también se realizaron entrevistas en parejas o grupos de tres personas ${ }^{35}$, por la facilidad que suponía para las personas entrevistadas realizarlas de esta forma y siempre con el objetivo de potenciar un ambiente que propiciara una buena comunicación. En estos casos siempre se realizaron entre personas que se conocían previamente y tenían una relación cercana.

Con todas las personas, junto con las entrevistas, se trabajó también con los Itinerarios. Sobre un mapa de tamaño DIN-A 3 de la ciudad de Manresa, se hizo marcar, con diferentes colores: un itinerario cotidiano en la ciudad, los lugares que les gustaban (diferenciando entre el día y la noche) y los lugares que no les gustaban (con la misma diferenciación). Los comentarios que surgieron de la realización de los treinta y un itinerarios también se tuvieron en cuenta como datos. Cabe destacar en este punto que lugares que en la entrevista no habían salido como relevantes ni frecuentados se resaltaron con este procedimiento por el hecho de verlos representados en el mapa.

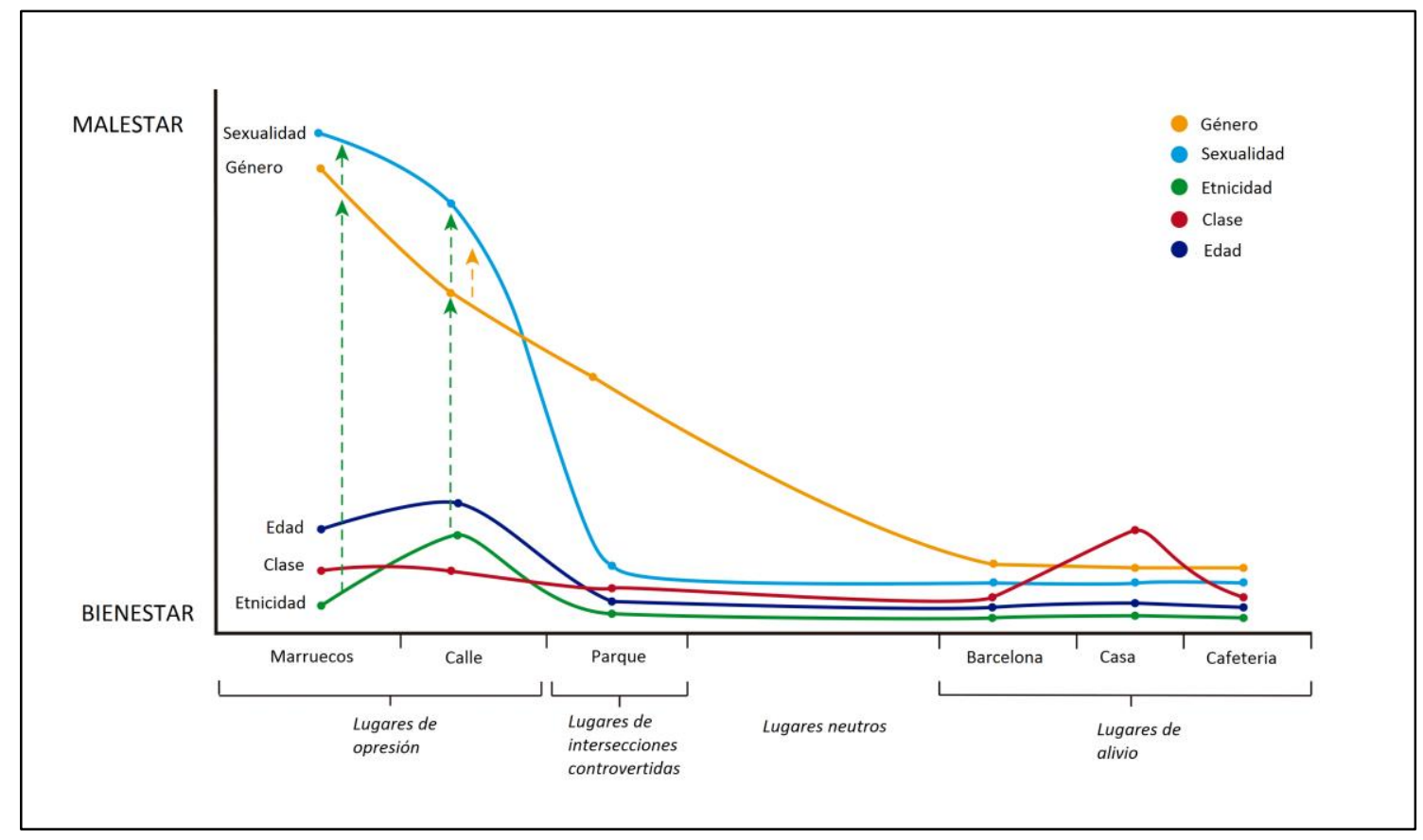

Figura 1. Ejemplo de Mapa de Relieves de la Experiencia.

Mapa de Fátima, chica lesbiana marroquí de 24 años.

Con doce de las treinta personas entrevistadas se realizó también otro tipo de metodología, los Mapas de Relieves de la Experiencia $^{36}$ (ver Figura 1). Esta metodología fue desarrollada a mitad del trabajo de campo por la necesidad de usar técnicas que permitiesen el análisis de datos sobre la interseccionalidad de forma sistemática. Esta metodología muestra de una forma visual datos que relacionan los lugares (la dimensión geográfica), las estructuras de poder (la dimensión social) y las experiencias (la dimensión psicológica). En un primer momento se diseñó esta

\footnotetext{
34 ver Rodó-de-Zárate y Baylina, 2014

${ }^{35} \mathrm{Se}$ realizaron nueve entrevistas individuales, seis personas en parejas, seis personas en grupos de tres y diez personas siguiendo la aproximación de Investigación-Acción Participativa.

${ }^{36}$ Para ver ejemplos sobre los Mapas de Relieves de la Experiencia (o Relief Maps en inglés) y un análisis más detallado sobre sus implicaciones metodológicas y teóricas ver Rodó-de-Zárate, 2013.
} 
metodología solamente para analizar y comprender con más detalle los datos ya obtenidos de las entrevistas. Con su elaboración se consigue sistematizar la información sobre qué tipo de experiencias (de malestar y de bienestar) se tienen en cada lugar y qué identidades son las causantes. Pero esta metodología no solo se dejó para el análisis de los datos sino que se volvió a algunas personas entrevistadas para que los realizaran ellas mismas, especialmente a aquellas que habían mostrado más interés o facilidad para colaborar, como también se hicieron elaborar en las entrevistas restantes. De esta forma, siguiendo un proceso determinado creado para ayudar a pensar sobre la propia experiencia desde una perspectiva espacial y interseccional ${ }^{37}$, se obtuvieron doce Mapas de los Relieves de la Experiencia, que también sirvieron como una rica fuente de datos para ser analizados complementariamente con las entrevistas y los itinerarios. Del resto de entrevistas yo misma realicé sus Mapas de Relieves de la Experiencia basándome en la información de las entrevistas.

Como se puede observar, las metodologías usadas han sido muy diversas. Durante el proceso de recogida de datos, el método fue adaptándose según las necesidades y en relación al objetivo concreto. La diversidad de aproximaciones y de técnicas ha permitido pues el acercamiento al tema de estudio desde ángulos diferenciados, lo que ha conllevado también un análisis más completo de las experiencias de la juventud en el espacio público. El hecho de preguntar sobre unos mismos datos en forma de entrevista oral, sobre un mapa de la ciudad y en forma de representación gráfica ha permito tener una gran cantidad de datos que han podido ser contrastados y analizados en su complejidad.

\section{Uso y experiencia interseccional en el espacio}

En la siguiente sección analizaré los malestares y bienestares que condicionan el acceso al espacio público de la juventud en Manresa. Con los datos obtenidos a través de estas metodologías, las experiencias que se relataron presentan una gran variedad. El primer resultado de la investigación es, pues, la constatación de la gran diferencia de experiencias que la juventud tiene en el espacio público debido, en gran medida, a las posiciones que ocupan en otras estructuras de poder más allá de la edad, aunque siempre en relación a ella. Con la intención de profundizar en las dinámicas interseccionales que provocan determinadas experiencias, el análisis se centrará tanto en ver los puntos en común como en resaltar las diferencias. Como fruto del análisis de los datos empíricos, esta sección se ha separado en tres partes referentes a tres factores determinantes de la experiencia en el espacio público: el miedo, el control social y la heteronormatividad.

\section{El miedo como limitación de acceso a la ciudad}

Uno de los principales factores determinantes de la experiencia en el espacio público es la cuestión del miedo. En general, la mayoría de las chicas identificó este factor como un gran condicionante de sus usos y experiencias, mostrando como tenían miedo en determinados lugares, a determinadas horas y en según qué circunstancias, hecho que las hacía modificar sus comportamientos. Por el contrario, la mayoría de los chicos no

\footnotetext{
${ }^{37}$ ver Rodó-de-Zárate, 2013
} 
mostró este tipo de sentimientos. Al contrario, muchos afirmaron sentir un alto nivel de bienestar en los mismos lugares y en las mismas horas en que las chicas sentían miedo. Las geografías feministas han estudiado ampliamente esta cuestión, argumentando que el género determina la libertad de movimiento en las ciudades por la percepción de miedo $^{38}$. Se ha mostrado también que las experiencias de miedo de las mujeres son producto de la violencia estructural ${ }^{39}$ y que este tipo de sensaciones no solo son respuestas a situaciones determinadas de violencia sino que funcionan como un recordatorio de la vulnerabilidad de las mujeres como socialmente producida ${ }^{40}$.

\begin{abstract}
Laia ${ }^{41}$ : A mi el Barri Vell m'encanta, però... Hi moments que et sents súper cohibida! Per la nit, jo per exemple, passar per allà sola, no hi passaria mai! No, no, no. I per exemple, per la Baixada dels Drets, tot lo que és les piscines el carrer aquell que s'endinsa, que surt a darrera de... No, no.
\end{abstract}

Cristina: A mi em fa molta ràbia, però és que jo em sento fatal!! Sola a la nit... És que no em sento gens còmoda... No em pararia al carrer $i$ em fumaria un cigarro... Perquè no vaig tranquil.la, tinc ganes d'arribar a casa... saps? I sentir-me bé... O tinc ganes de trobar-me algú... I anar acompanyada... Perquè generalment no vaig gens còmoda... No passejo. Vaig en plan, vaig a casa... No. No és por, no em sento tranquil.la, saps? Hi vaig ràpid. No hi vaig tranquil.la i em pararé allà $i . .$. Hi aniré, però no súper tranquil-la com si hi anés ara, saps?

Teresa: Per exemple, a mi a vegades m'agafa la paranoia de a veure si em violaran algun dia... No vaig cada dia amb aquesta por, però sí que si un dia llegeixes algu, aquella nit quan surts del bar, penses... A viam si...

En estas citas se puede ver claramente una experiencia de malestar en el espacio público. La sensación de represión e incomodidad, el miedo a posibles agresiones sexuales y la intranquilidad son factores que claramente determinan por qué lugares pasar y de qué forma. Si bien algunas no lo definieron como 'miedo', el hecho de concebir la calle como un lugar de paso, un lugar dónde no se quiere estar, como afirma Cristina, muestra la importancia del 'cómo' se está en los lugares. El uso del espacio público está controlado a través de prácticas espaciales ${ }^{42}$, pero el acceso a este no es solo una cuestión de presencias y ausencias sino que la experiencia concreta que se tiene, en este caso de malestar, es también una forma de exclusión. El hecho que las chicas jóvenes estén sujetas a un dominio visual masculino y heterosexual las sitúa en una posición de objetualización, y la internalización de esta mirada actúa como un panóptico que disciplina sus cuerpos, ya sean vistos o no ${ }^{43}$.

Pero mientras para las chicas la calle de noche representa un lugar incómodo, un lugar dónde, aunque no sientan un miedo intenso, quieren pasar deprisa, para muchos chicos supone una experiencia bien diferente.

David: És un lloc on desconnectar de tota l'activitat rutinària... Bueno, vull dir, de tots els llocs tancats que una miqueta respresenten la rutina diària, les obligacions com poden ser la universitat, la feina, el què sigui... el moment que surts al carrer, l'espai públic, són moments de desconnexió, que pots llegir tranquil. Pots anar a passejar, a passar l'estona... I clar, hi trobes una llibertat més personal. Vull dir, un contcte més amb tu mateix, com qui diu.

\footnotetext{
${ }^{38}$ Pain, 2001; Koskela, 1997; Ruddick, 1996; Valentine, 1992

${ }^{39}$ Pain, 2001

${ }^{40}$ Koskela, 1997

${ }^{41}$ Todos los nombres han sido modificados para mantener el anonimato de las personas entrevistadas.

${ }^{42}$ Ruddick, 1996; Pain, 2001; M. E Thomas, 2005, Ehrkamp, 2013

${ }^{43}$ Valentine, 2000
} 
Pere: De nit és molt millor. Sol, caminant per on sigui, tornant de festa o anant-hi, a mi és algu que m'agrada molt. Amb la música, tranquil-lament, vas fent, i és una sensació molt bona.

Maurici: Bueno, a mi m'ho passo pipa passejar pel carrer. A vegades camino sense tenir cap mena de direcció. Però bueno. No sé, per exemple el Barri Antic sempre és canviant absolutament. Tant d'olors com de...

Como se puede ver es estos casos, la calle de noche en Manresa puede representar un lugar de bienestar, de tranquilidad y de placidez. No es solamente la ausencia de miedo sino la posibilidad de tener experiencias enriquecedoras. La calle se vuelve para estos chicos un lugar íntimo y de introspección. Además, con el ejemplo de estas experiencias, la tradicional distinción entre el espacio público y privado se ve transformada, confirmando la idea de que el refugio que podría suponer el hogar como espacio privado, para la juventud (o una parte de ella) se encontraría en la calle (el espacio público) de noche y lejos de la mirada de las autoridades adultas ${ }^{44}$.

Delante de este tipo de situaciones, algunos estudios han mostrado que las chicas buscan lugares protegidos como centros comerciales o cafeterías donde estar seguras ${ }^{45}$. En las entrevistas, las chicas también usan lugares considerados más seguros, como bares, a pesar de que los acosos en discotecas y bares nocturnos por parte de chicos son una experiencia bastante común en las entrevistas realizadas. Pero, ¿ningún chico siente miedo por la noche? Algunos sí. Es el caso de un par de chicos gays que afirmó tener miedo en el barrio antiguo de la ciudad. Tanto en sus Mapas de Relieve de la Experiencia como en sus itinerarios marcaron esta zona como una zona de malestar, un lugar que no les gustaba sobretodo de noche. Sus estrategias para no pasar miedo en estos espacios pasan por la representación de una masculinidad hegemónica y por evitar mostrar afecto a otro hombre. Se profundizará sobre esta cuestión concreta más adelante, pero en referencia a las actuaciones contra el miedo, aparecieron una gran cantidad de estrategias para minimizar posibles agresiones, hecho que muestra su capacidad de 'aprendizaje de la calle' ${ }^{46}$. Como argumenta Caitlin Cahill ${ }^{47}$, la juventud demuestra tener grandes habilidades para leer el entorno social y espacial, y la forma en que estas chicas gestionan el espacio y el entorno en relación al miedo muestra esta pericia.

Nadia: Si vius allà no et diuen res, si passes et diuen guapa no sé què no sé quantos. A mi em
passava al principi, que feien una mica els tontos i després un dia, al entrar estava nerviosa no
sé per què i em vaig trobar un dient eh, guapa, no sé què, oyé!! I em vaig posar a cridar i des
d'aquell dia no em parlava, des d'aquell dia no em van dir res! Li vaig 'oye que tu no me conoces
yo soy muy peor que tu! Que tu no me conoces! Estava dient això però les cames mestaven
temblant però bueno eh! Que sóc la forta, eh, no et fiquis amb mi! I em va dir, ya está tranquila
que me voy, que me voy.

Cristina: Jo no em sento segura, sola pel carrer, a la nit. Sempre vaig amb les claus aquí, eh, me les fico així a la mà... I amb el mòbil a l'altra butxaca! Clar però és que no esperes... Jo el dia que anava pel passeig $i$ tenia aquests quatre darrera, mirava a banda i banda un lloc on poder entrar, on hi hagués gent. Hauria desitjat un bar o un Ateneu o...

\footnotetext{
${ }^{44}$ Valentine 2000

${ }^{45}$ Taylor y Addison, 2009; Thomas, 2005, Koning, 2009

${ }^{46}$ Traducción propia del inglés 'street literacy'.

${ }^{47}$ Cahill, 2000
} 
Como se puede ver en las citas, la percepción del miedo va acompañada del desarrollo de determinadas capacidades que pueden evitar agresiones. Llevar las llaves en la mano, responder con contundencia o conocer el espacio en el que se mueven son herramientas que les dan seguridad. Otras estrategias de gestión espacial del miedo tienen que ver, por ejemplo, con la percepción que caminar hacia un lugar con facilidad para abrir la puerta reduce el miedo, en relación con lugares que precisan de llaves que pueden ser difíciles de encontrar o de usar en un momento de tensión. Como relató Cristina, ir en dirección al bar le da menos sensación de miedo que ir hacia casa. En este caso, la rigidez de la separación entre lo público y lo privado es un factor determinante para su bienestar en la calle. Es decir, la separación física rígida entre espacios aumenta su sensación de miedo, mientras que los lugares dónde la separación es menor (porque la puerta está abierta o es fácil de abrir) disminuyen esta sensación. Junto con este ejemplo, otra chica afirmó que el hecho de que en verano las ventanas están abiertas le produce más seguridad, ya que en caso de tener que pedir ayuda, alguien podría oírla. La porosidad/rigidez de la separación entre público y privado se materializa así físicamente en los espacios con las experiencias de estas chicas. Y su conocimiento sobre estas dinámicas espaciales demuestra su capacidad para gestionar los espacios en favor de su seguridad. Su posición respeto a posibles agresores, las posibilidades de salir corriendo, las características concretas de las calles y el mobiliario urbano también condicionan su bienestar, pero a la vez pueden servir como elementos estratégicos para defenderse.

Otros ejemplos que demuestran este conocimiento de las calles es la gran 'pericia espacial' y los complejos criterios que usan para escoger sus lugares de seguridad o evitar lugares potencialmente peligrosos:

\begin{abstract}
Marina: O també per anar a la plaça Sant Jordi, que hi ha com... L'hospital aquest on hi havia el [bar]... que hi ha unes escales... Que hi ha un carrer que travessa... Jo quan era més petita, en comptes d'anar pels drets anava per allà perquè em sentia més segura perquè no hi havia ningú.
\end{abstract}

\begin{abstract}
Aina: [Al carrer de les Saleses] jo no hi vaig mai. Em fa tope por. És que clar, és un carrer que hi ha murs, és un carrer vertical, que hi ha murs de que tu entres al carrer fins que surts, tot són murs, vull dir, que no te'n pots anar... I hi ha bastants angles morts. Vull dir, que tu potser vas així $i$ està amagat a la cantonada $i$ tu no el veus fins que no trenques. A mi el què em fa por és que si et passa algu només te'n pots anar cap amunt o cap avall, no te'n pots anar cap als costats... Si et passa al carrer Santa Maria, saps que al mig hi ha la plaça de la Música, que per allà et pots escapar... Allà et quedes atrapada.
\end{abstract}

\begin{abstract}
Alba: Em sento com més oberta a la ciutat. Perquè com que Manresa no té cap espai que tinguis una perspectiva més aèria de la ciutat i que sigui verd i que sigui segur... Perquè el què m'agrada d'aquell espai és que estàs molt a prop de la carretera de Vic... També és com que en un moment donat baixes les escales i estàs a la plaça Europa. En canvi, un lloc on tindries la mateixa vista és el Parc del Castell. Però al Parc del Castell, a les nou del vespre o a les deu del vespre a l'estiu... Bueno, anar-hi sola no hi he anat mai. Però no hi he anat mai perquè em fa por. Perquè és un lloc que està massa aïllat com perquè tu puguis marxar corrents a demanar socors. En canvi, aquell espai m'agrada perquè et dóna una perspectiva aèria, hi ha gespa, cutre, però hi ha gespa, quatre arbres... I m'agrada assentar-me allà a mirar els cotxes $i$ mirar la gent $i . .$.
\end{abstract}

En estos casos se muestra como la elección de sus itinerarios cotidianos y los lugares de bienestar responde a criterios tan diversos como el número potencial de personas en cada lugar, la existencia de escaleras, la anchura de la calle, la existencia de ángulos muertos o esquinas, las posibilidades de escapar hacia varias direcciones, la visibilidad 'aérea', la proximidad con calles concurridas (como la carretera de Vic), el tipo de gente 
que usa cada lugar, etc. Son abundantes la citas en las que las chicas muestran una gran variedad de criterios espaciales complejos para gestionar su miedo y, en definitiva, su seguridad. Su manejo casi automático de estas variables las guía por las calles de Manresa, reduciendo su sensación de miedo y contribuyendo a su uso de la ciudad.

El miedo, pues, es un factor determinante para el acceso de las chicas a los espacios públicos, especialmente de noche. No pararse, cambiar el ritmo, modificar los horarios, condicionar los planes, redefinir las rutas y los itinerarios, suponen restricciones al acceso al espacio público en este caso determinadas por el género. La intensidad del malestar que generan determinados lugares y la necesidad de encontrar alternativas no debe leerse solamente como una restricción individual sino que es una discriminación de género que limita el acceso al espacio público. Pero, analizando los datos de forma interseccional, el género no actúa independientemente de otras categorías.

Aunque en los estudios de juventud y con la actual situación de crisis es difícil definir exactamente cual es la posición objetiva de clase de la gente joven, la clase social es un factor relevante para condicionar el miedo. Por ejemplo, el caso de Mercè, una chica blanca de 28 años trabajadora de la empresa familiar y residente en un barrio de estatus socioeconómico medio-alto, muestra la relación entre el género, la clase social y el miedo.

\begin{abstract}
Mercè: Jo, per exemple, per La Seu o la Cova o tota aquella zona d'allà, sola a la nit em fa basarda. O el barri Vell... Ja sé que no em passaria res, però sóc una persona poruca, no, no. Mira, ahir mateix, estava molt cansada, tenia fred, no, no, no estava bé. I em deia ella, 'va, pugem caminant', $i$ jo, no, $i$ vaig trobar un taxi a mig camí $i$ vaig pujar al taxi $i$ li vaig dir, 'si vols pujar vine i si no, no. El taxi ja el pago jo'. Perquè vaig pensar, si ara t'atraquen, portava peles a la cartera, si ara t'atraquen... no, no. I penso, passaràs fred, passaràs por, aniràs llufada i a sobre encara acabaràs contracturada dels nervis que hauràs agafat per pujar a casa! Pues t'agafes un taxi, cinc euros i goita.
\end{abstract}

Como ella señala, el barrio antiguo es un lugar que le da miedo pero es dónde están algunos bares y restaurantes que le gusta frecuentar. Normalmente procura ir a bares en otras zonas de la ciudad, pero cuando se dirige al centro acostumbra a usar un taxi para volver a casa. Su posibilidad de tomar un taxi es pues un elemento que disminuye considerablemente su miedo al volver a casa de noche. Como contraste, se encuentra el caso de Ainhoa, una estudiante blanca que reside con su familia en el barrio del Xup, un barrio dónde actualmente viven mayoritariamente inmigrantes procedentes de Marruecos y América Latina. Este barrio se encuentra a unos tres kilómetros del centro de la ciudad, encima de una colina a la que se llega por una carretera. La falta de transporte público nocturno impide a Ainhoa salir de noche por Manresa si quiere tomar bebidas alcohólicas, ya que no puede permitirse pagar un taxi cada fin de semana. Sus estrategias son diversas, pero sus formas de ocio quedan condicionadas por el barrio dónde vive, su clase social y su género. Como ella afirma:

\footnotetext{
Ainhoa: I jo al Xup, hi ha bus cada mitja hora, però l'últim surt de Manresa a les deu $i$ vint. Clar, si vols quedar-te ara a l'estiu a fer una birra... Has d'agafar un taxi? Sis euros des del Puerto Rico al Xup. La gent no acostuma a pujar a pota. És una carretera hiperllarga, camp, camp, els barris una mica apartats... Clar, és com molt solitari. Jo de día sí, però de nit mai hi he pujat. En canvi el meu cosí sí. Se'n va de festa i puja caminant.
}

Así, la clase es un factor que constituye la forma como se experiencia el género, en este caso en relación a la sensación de miedo y, mayoritariamente, en fines de semana por 
motivos de ocio. Pero no todas las chicas entrevistadas perciben el miedo en la ciudad de la misma forma. Por ejemplo, Alba, una chica de 21 años, blanca y heterosexual, afirma que durante un tiempo sintió menos miedo en la calle que en su casa familiar debido a los conflictos y a la autoridad que sus padres ejercían hacia ella.

\begin{abstract}
Alba: Si és que també depèn molt, però si tu en teoria el teu espai privat on tu t'has de sentir segura, no hi estàs a gust... A mi m'ha passat. Estava una època a casa meva... M'hi sentia súper malament. No tenia gens de ganes d'arribar a casa i realment, si havia d'anar a una lloc que potser tardava deu minuts per arribar a casa meva, me n'anava a fer una volta que potser tardava mitja hora per arribar més tard a casa i em sentia més a gust, encara que fossin les onze, al carrer, que no pas a casa. I no em sentia gens, gens segura. En canvi, em sentia... No és que em sentís insegura, però em sentia molt més tranquil.la i a gust que a casa que sabia que tindria merders $i$ bronques. I en canvi el carrer era un lloc per refugiar-me de tots aquests mal rollos. I m'estava molta estona, la màxima que podia, al carrer, abans d'evitar-me una bronca, m'estava al carrer caminant.
\end{abstract}

Esta situación muestra como el uso y el significado que se da al espacio público está determinado por el espacio privado. Uno no se entiende sin el otro. Muchas feministas han mostrado como el hogar puede ser un lugar de violencia y malestar, a pesar de las connotaciones positivas que ha tenido en la geografía el hecho de considerar el hogar como un espacio de identificación ${ }^{48}$. A pesar de considerar este hecho, desde el feminismo negro también se ha cuestionado el hecho de que solo se entienda la casa como un lugar de opresión para las mujeres ya que para muchas mujeres negras el hogar significó un espacio de resistencia y reafirmación ${ }^{49}$. En este caso, la situación que vive Alba en el espacio privado modifica tanto el uso como la experiencia que ella tiene de la calle, mostrando la estrecha relación entre los dos lugares para determinar la experiencia.

Esta diferente percepción del miedo también se encontró en algunas de las entrevistas a chicas marroquíes. Para algunas de ellas, el miedo a una agresión sexista en el espacio público no se percibía como una experiencia cotidiana, o ni siquiera conocida:

Fatima: Nunca he probado si tengo miedo. Mi marido no me deja salir de noche, solo por la Festa Major, que salgo con él hasta la una.

Aya: Por la noche no se. Marido casa, hacer comida...

Fátima vive en el barrio antiguo de la ciudad con su marido y afirma no haber sentido nunca miedo en el espacio público. A pesar de su edad y su género, su religión y su origen hacen variar la experiencia que tiene del espacio público. Al no poder salir de noche, no siente miedo. Esta cita pone de manifiesto que no solo el género es el que determina el miedo en la calle sino que hay otras identidades en juego. Este ejemplo de dinámica interseccional no solo muestra que no todas las mujeres sienten miedo en la calle sino que también pone de relieve que, en los casos anteriores, el tipo de uso del espacio público (salir de noche los fines de semana) determina estas experiencias, y las prácticas culturales específicas de las chicas blancas son esenciales para comprenderlas.

A pesar de que Fátima afirma no tener miedo en el espacio público, Nadia, una chica marroquí de 16 años tiene otro tipo de experiencias. Ella vive con su familia en la Baixada dels Drets, una calle identificada por la mayoría de las chicas en los mapas de

\footnotetext{
48 ver Rose, 1993

${ }^{49}$ hooks, 1990
} 
los itinerarios como la que provoca más miedo de la ciudad. Es una calle dónde el tráfico de drogas y los conflictos entre grupos son habituales, como cuenta la misma Nadia:

\begin{abstract}
Nadia: On visc jo. Saps on està la Baixada dels Drets? Doncs allà. No m'agrada gens ni mica! No, no sé, està molt malament allà, perquè venen drogues no sé què $i$ hi ha molts marroquins molt mal educats $i$ cada dos per tres hi ha la policia allà buscant $i$ agafant... Cada dos per tres quan passo per allà em demanen el DNI, a l'estiu sempre estan allà, i tanquen per aquí, al camí, a dalt i a baix. I després entren els mossos per les escales $i$ busquen les drogues i no sé què $i$ agafen als nois... I clar, si vols passar per aquí, clar jo visc allà, al centre de les escales, i per passar tinc que ensenyar el DNI com si fos que estic en un altre país. I $m$ 'ha passat moltes vegades, o tinc que esperar allà fins que acabin. Un dia em va passar que vaig arribar a casa a les sis i no vaig entrar fins a les vuit!
\end{abstract}

Ella tiene miedo en su propia calle debido al comportamiento de determinados hombres en esa zona y debido también a las actuaciones policiales. En este caso, ella sí usa el espacio público de noche, pero el lugar dónde vive y su origen condicionan su experiencia de una forma concreta. Amina, una chica lesbiana de origen marroquí de 25 años, también afirma percibir miedo en el espacio público aunque, por su orientación sexual, tenga una experiencia diferente. Para ella, el hecho de dar muestras de afecto a su pareja, una mujer blanca, es el que desata el control sobre su cuerpo y sus acciones en el espacio público. Aunque, como se puede ver en la cita, ella responde a las miradas con una actitud desafiante:

Amina: Sí, han passat uns marroquins al costat, s'han parat, bueno estàvem per aquí pel Passeig, bueno, pues tenia ganes de fer-li un petonet. Li faig un petonet $i$ just passen uns marroquins is 'han parat. Vaig girar, vaig dir 'buuuu'.

Estos casos muestran como las identidades que juegan un papel en la determinación de las experiencias de estas mujeres de origen marroquí son diversas, y que sus dinámicas interseccionales son complejas y cambiantes, hecho que contrasta con discursos hegemónicos y homogeneizantes sobre las mujeres musulmanas. No es solo su origen, sino que su género en relación con la edad, la sexualidad o la clase social constituyen su experiencia concreta del espacio público y limitan o facilitan el acceso a él.

Así, en el caso del miedo, el género destaca como factor determinante que restringe o permite el acceso al espacio público. El miedo, como se ha visto, no es solamente una respuesta directa a la violencia sino el resultado de la producción social de la vulnerabilidad de las mujeres. Las mujeres lo experiencian de forma diferente entre ellas y también en relación a los hombres, lo que comporta formas diferentes de percibir y estar en la ciudad. En el caso de los chicos, el hecho de poder estar en la calle a diferentes horas y sentir bienestar es un privilegio de género que en la investigación llevada a cabo se muestra como elemento fundamental. El acceso al espacio público, entendido no solo como la posibilidad de estar en determinados lugares sino como el poder estar bien en los espacios públicos, debe ser entendido como un privilegio. Así, el hecho de que determinadas personas por su posición en determinadas estructuras de poder no puedan estar bien en el espacio público debe entenderse como una discriminación.

\title{
El cuerpo visible y el control de la comunidad
}

Como ya se ha comentado, la ausencia de experiencia de miedo en el espacio público por parte de las mujeres jóvenes marroquíes es un hecho relevante a tener en cuenta para 
el análisis sobre la experiencia que tienen en él. Esta ausencia de malestar es debida a la falta de uso del espacio público en determinados momentos, pero su malestar en la calle tiene unas causas diferentes: el control social que ejerce su propia comunidad. El caso de Aya, mujer marroquí de 27 años, madre de una niña de seis meses y residente en el barrio antiguo muestra esta situación, como también el caso que relata Fátima.

Fátima: Me gusta salir. Pero mi marido no me deja salir porque nosotros somos musulmanes y la religión musulmana no deja que las mujeres salgan a la calle. Yo tengo miedo de mis paisanos, porque si me ven, mi marido se enfada. Los marroquines, cuando ven una mujer casada y con marido que sale a la calle con pelo [sin velo], hablan mal "mira, está casada, está así...". Por eso...

Aya: Cuando he llegado a España, yo no he dejado el Marroc! Mismo que mi país! El mismo. Mucha gente, muchos marroquins... España es Marroc! Muchos marroquís! ¿Dónde es español? ¿Dónde? Muchos marroquins! [risas].

Sus restricciones de acceso al espacio público limitan su presencia en él, como se puede ver en las citas, pero no solo impiden que salgan a la calle sino que cuando están en ella tampoco están como les gustaría. El hecho de sentirse observadas y juzgadas y temer una represalia por parte de sus maridos si son vistas es una restricción a su acceso pleno al espacio público. Sentir las miradas de su propia comunidad como control a su posibilidad de movimiento es su experiencia cotidiana, pero, como ellas cuentan, tienen sus propias estrategias de transgresión de estas limitaciones:

Fatima: Con mis amigas voy a panaderías escondidas. Busco sitios donde no hay hombres musulmanes. Sitios escondidos y sin alcohol.

Fátima camina hacia otro extremo de la ciudad para ir a una cafetería donde puede charlar con su amiga lejos del control de su comunidad. Este refugio muestra su capacidad de gestión del control a través de los espacios, como en el caso de Amina, que también escoge una cafetería de la calle más comercial de Manresa como su refugio personal:

Amina: Pos, mira, per aquí Manresa el meu bar preferit és aquest, saps? El trobo molt tranquil, no hi ha marroquins, saps? No m'agobien... M'agrada el Parc de l'Agulla... I ja està.

Amina encuentra en un lugar donde no hay personas de su origen como un lugar de tranquilidad. A pesar de no ser un lugar especialmente frecuentado por lesbianas, que la clientela sea de edades muy superiores a ella y con precios elevados, la diferencia supone para ella bienestar.

En los casos de las chicas marroquíes, la negociación espacial parece ser pues un elemento fundamental de gestión de sus identidades culturales y de género. Por negociación espacial me refiero aquí a la capacidad de gestionar los malestares que les producen sus identidades a través de los lugares. Esta negociación es tanto la creación de lugares de alivio como la identificación de los lugares de malestar y las consiguientes estrategias que llevan a cabo para mitigar sus experiencias negativas en función de las intersecciones entre sus identidades. En el caso de Fátima y Aya, las restricciones que sufren y la forma como ellas las gestionan muestran la importancia del componente espacial. Como ya se ha visto, el hecho de poder salir a la calle es el primer determinante, pero la forma como salen también es un tema de negociación.

Fátima: Sin maquillaje, vestir... En la casa puede hacer todo lo que quiera la mujer, pero cuando sale de la puerta tiene que vestir bueno, que hacer la ropa de así... 


\begin{abstract}
Aya: Sí, solo pequeña ropa para marido, si. la calle va esto [el vestido] hasta aquí [los pies]... Va muy largo, no hacer maquillaje... Pero hay muchas mujer no quieren... libertad. Hay muchas mujer quieren libertad. Muchas mujeres no quieren, libertad, vestir ropa por aquí o por aquí [corta], no quieren pañuelo... [...] Solo hombres miras tu mujer. Marido puede mirarme sin ropa, pero otro hombre no! Cuando todos hombres miras todos mujeres, todas mujeres sin ropa... ¿Qué? Todos hombres mira este cuerpo, ¿marido qué mira? ¿Por qué casado con este mujer? Yo mirar todo! Cuando no mirar, yo casado, por mirar. Yo casado este mujer para mirar! Si! Mirar, tocar... [risas]. Y cuando con ropa, oh, casado por mirar y para mi mirar cuerpo, mirar, yo solo tocar no todos tocar, todos mirar como camina. Cuando hay una cosa como oro, como diamante, también la mujer como diamante. Una cosa muy... Cuando puedes todos tocar no puedes, no es diamante, es como... Cuando así una cosa muy buena. Como diamante, si? ¿Entiende?
\end{abstract}

En estas citas se puede ver como su cuerpo es en sí mismo un lugar atravesado por las relaciones de poder. El tamaño y forma de su ropa, el maquillaje, la (in)visibilidad de su cabello, son elementos con diferentes significados y con los que negocian sus diferentes identidades. Como se puede ver en la cita, la mirada masculina juega en estos casos un papel fundamental en la identidad de estas mujeres, en palabras de Gillian Rose:

The threatening masculine look materially inscribes its power onto women's bodies by constituting feminine subjects through an intense self-awareness about being seen and about taking up space ... [I]t is a space which constitutes women as embodied objects to be looked $a t^{50}$.

La actitud de Aya en relación a la mirada masculina pasa por limitarla a la de su marido. El sexismo del que habla Rose se mezcla con la heteronormatividad y la monogamia, haciendo de su cuerpo un campo de batalla en el que se inscriben las normas de género a través de la mirada masculina. En el siguiente caso se muestra la otra cara de la moneda, las consecuencias del cuerpo visible.

\begin{abstract}
Marina: Jo visc, bueno, per la "perifèria" i per anar al centre he de passar pel Barri Vell, que està ple de moros, $i$ tots em deien coses sempre i a l'estiu sí que vas en tirants i d'allò... I jo no sóc una persona que vaigui molt fresca, tampoc. Ni a l'estiu, ni... no. I et diuen coses, i sempre... I és allò... És que fa fàstic, tio! Perquè no. Una cosa és que et diguin: "Eh, guapa!". I passes, i... Mira, i fa ràbia... I... Però bueno. I hi ha coses que fan... No sé, a mi m'han arribat a agafar i... saps? Vull dir, situacions que fas un "a veure!"
\end{abstract}

En este caso, Marina muestra como su cuerpo visible es un lugar de contestación. Ella identifica 'los moros' como los responsables de este tipo de agresiones físicas y verbales sobre su cuerpo, hecho bastante recurrente en las entrevistas. Si bien en las entrevistas las agresiones no han sido solamente de hombres de procedencia marroquí, en el imaginario de la mayoría de las chicas si se identifica este colectivo como uno de los principales miedos.

Pero, ¿cómo viven los chicos jóvenes de origen marroquí esta situación? La entrevista con Ahmed y sus Mapas de Relieves de la Experiencia muestran que no siente malestar en ninguno de sus lugares cotidianos. Este chico de 16 años va a la escuela y ayuda a su familia en su negocio de comestibles. No identificó ningún lugar de malestar pero sí algunos de bienestar, entre ellos su casa y "El Riu” (el parque a la orilla del río Cardener, cerca del Barrio Antiguo de Manresa). En su casa muestra como su edad y la autoridad de su madre y su padre le impiden realizar algunas actividades. En cambio, "El Riu"

\footnotetext{
${ }^{50}$ Rose, 1993, p. $145-146$
} 
aparece como refugio dónde va a reflexionar, lejos de distracciones (tiene dos hermanas $\mathrm{y}$ un hermano menores). El hecho de no identificar el barrio ni el hogar como lugares de malestar y el hecho de que su género o su religión no fueran cuestiones problematizadas muestra como la perspectiva interseccional es imprescindible para entender el funcionamiento tanto del origen, la etnia o la religión en relación al género. Y por su edad, Ahmed no es visto como 'potencial agresor', lo que también muestra como la edad es un factor relevante en la construcción de determinados estereotipos racistas, como lo es, evidentemente, el género.

Podría parecer que el hecho de ser mujer y procedente de otro país supone un problema de control social por parte de su comunidad de origen, pero no siempre sucede así. En el caso de Elena, una chica Colombiana, trabajadora doméstica, de 23 años, poder reunirse con otras personas originarias de Colombia supone una fuente de seguridad y de diversión. Como ella misma comenta sobre los encuentros futbolísticos de los sábados:

Elena: El lugar que más me gusta es lo del Congost. Mi marido juega allí a futbol, juega todos los fines de semana. Juega en los equipos de latinos, hacen campeonatos y eso. Hacen varios equipos, yo voy a verlo. Y van muchas mujeres, mucha gente. Nos lo pasamos bien. La gente acaba el partido y se queda más tiempo a conversar, a tomar algo o así.

Este lugar muestra como el encuentro con personas que comparten su mismo origen crea un espacio de bienestar. La separación de roles y de actividades por sexo es clara en estos encuentros, pero para ella éste es un espacio de alivio. La creación de lugares en los que se comparte una identidad como lugares de bienestar también se encontró con la creación de espacios solo para jóvenes. Las chicas entrevistadas pertenecientes al colectivo feminista Acció Lila afirmaban que el Ateneu Popular la Sèquia, una casa okupada en el centro de Manresa, suponía un lugar de libertad para la juventud. La autogestión y la posibilidad de decidir qué actividades se realizan con autonomía supone un lugar de emancipación. Por ejemplo, una pareja de lesbianas que frecuentan este espacio relató que ese era el único espacio en la ciudad donde podían mostrarse afecto abiertamente, ya que al ser solo para jóvenes no temían que sus padres (o otras personas adultas conocidas) frecuentaran el lugar.

Edurne: Per exemple ella i jo aquí tampoc no és que ens haguem d'amagar molt, no? Tampoc ens estem aquí tot el rato que passem juntes... Algun cop estem juntes però vull dir... Si li he de donar un petó o el què sigui, pues li faig.

Maria: I en un bar d'un altre tipus no ho feu?

Edurne y Tina: No!

A parte de la ausencia de personas mayores, la creación de un espacio político dónde no se toleran determinadas actitudes sexistas, racistas o homófobas les ayuda a sentirse más seguras. Algunas chicas reconocieron haber sufrido agresiones sexistas en este lugar, pero también percibían que el hecho de estar en un espacio en el que la mayoría de la gente las apoyaría suponía un bienestar en cuanto a sus posibilidades de reaccionar a actitudes machistas y ser apoyadas por el resto.

El hecho de que este espacio de jóvenes signifique un lugar de seguridad y de libertad para las chicas lesbianas muestra como otros lugares de la ciudad no les proporcionan este bienestar. Con todas las entrevistas realizadas a lesbianas y gays, su orientación sexual aparecía como el factor determinante de malestar, significando grandes 
diferencias con las personas heterosexuales entrevistadas. En el siguiente apartado analizaré esta cuestión con más profundidad.

\section{La heteronormatividad como causa de malestar}

Teresa: No ens ha passat mai res perquè mai... Mai hem anat tranquil.les pel carrer.

Esta frase de una chica blanca lesbiana de 26 años, camarera y que vive con su novia, pone de relieve la intensidad con que vive la represión de la heteronormatividad en el espacio público. Nunca han podido ir 'tranquilas' por la calle por el hecho de ser una pareja de mujeres. Teresa cuenta que ya sea por ella o por su pareja (esto a veces es motivo de conflictos) nunca se muestran afecto en la calle, hecho que les permite pasar como amigas, como heterosexuales, evitar ser reconocidas como lesbianas. Ella atribuye este tipo de actuación a la prevención de una posible agresión o el estar sometida a las miradas de la gente, sentirse observada e incomodada. Este tipo de actuaciones se encontró en todas las entrevistas hechas a lesbianas y gays. A continuación se pueden ver algunos ejemplos.

Edurne: Pel carrer anem com amigues. Actuem normal, com si fóssim amigues, tampoc tenim la necessitat d'anar agafades de la mà o el què sigui.

Ainhoa: Tampoc aniràs allà al Barri Vell de Manresa donades de la mà o fent-te un petó, perquè bueno, perquè saps lo que t'hi pots trobar. Llavors també és una mica... Metamorfosear amb l'entorn.

Teresa: És pel simple fet del què dirà la gent i què... Que es quedaran mirant $i$ et senyalaran... És aquesta por. [...] I ella [la nòvia] això de mostrar-se no, creu que és un espectacle. Tenim discussions...

Andrés: Jo no he tingut mai cap problema [...] Pero yo si tuviera que ir cogido de la mano o asi nunca me metería por las Escodines ni un sitio de esos... Jo agafat de les mans, abans, a ningún lloc. Ara ja una mica més... Una vez me cogió de la mano y casi le parto la mano! Me sentía súper incómodo. Es que en Manresa ni de coña.

Estos casos muestran la heteronormatividad en el espacio público y la normalización de la discriminación. Se asume que 'lo normal' es ir como amigas, que en determinados lugares no se pueden dar muestras de afecto, que la presencia de una pareja de lesbianas es 'un espectáculo' o, como relata Andrés, el no haber tenido nunca 'ningún problema' por ser gay pasa por aceptar no darse de la mano con su pareja. La estrategia más recurrente para hacer frente a esta situación es el 'passing', pasar como heterosexuales. La discriminación que podrían sufrir por mostrar afecto en espacios públicos es evitada a través de una representación 'adecuada' a las normas de género. Sin mostrar afecto a una persona del mismo sexo y representando el género acorde con la feminidad o masculinidad hegemónicas, se evitan las agresiones o posibles comentarios. Cuando se compara con los comentarios de personas heterosexuales se ve como este proceso implica una modificación sustancial de la experiencia en los espacios.

Mercè: A no! Jo em sento bé a tot arreu amb això! És que no... Si, clar, a tot arreu molt bé. 
La sexualidad no normativa es algo a esconder en el espacio público para evitar agresiones ${ }^{51}$ mientras la heterosexualidad goza del privilegio de la norma en las calles manresanas. En las entrevistas a heterosexuales, la cuestión de la sexualidad no era un tema recurrente para hablar sobre sus experiencias de malestar en el espacio público. Aunque con la elaboración de los Mapas de Relieves de la Experiencia se preguntó sobre esta temática, las respuestas acostumbraban a ser rotundas y claras: su heterosexualidad nunca ha sido un problema en el espacio público. De hecho, en algún caso, la normatividad de la heterosexualidad se reflejó en el hecho de que no consideraban tener que rellenar la columna de la sexualidad (en una parte del proceso de creación de los Mapas de Relieves de la Experiencia) por 'no tener' o por 'ser normales', hecho que demuestra como algunas identidades se construyen como 'las otras' mientras la heterosexualidad permanece como la norma, invisibilizando su especificidad.

Pero, aunque la represión en estas citas es previa a la limitación expresa de estar en determinados lugares, también se narraron algunas situaciones en las que la negativa a permanecer en un establecimiento había sido expresa y directa:

\begin{abstract}
Ainhoa: I un cop estàvem esmorzant en un bar i no vam fer-nos un petó ni res. Estàvem així agafades de la mà parlant de no sé què i el senyor de bar va venir i ens va invitar a marxar del bar!
\end{abstract}

Estos casos reafirman la idea de que el espacio público está construido como heteronormativo y que se (re)produce como si preexistiera como heterosexual ${ }^{52}$, causando malestar a aquellas personas que no encajan en la norma heterosexual. El hecho de tener que decidir en cada momento si pueden mostrar o no su orientación sexual es en sí misma una discriminación, ya que limita su derecho a la ciudad, su derecho a poder expresarse en el espacio público sin constreñimientos.

A pesar de que esta situación puede darse con lesbianas y gays de diversas edades, la relación de dependencia con las familias de las jóvenes entrevistadas condiciona su experiencia del espacio público. En los estudios sobre la situación de lesbianas y gays en relación con sus familias, el hogar familiar acostumbra a ser un lugar dónde se experimentan las consecuencias negativas de su orientación sexual ${ }^{53}$ mientras que la casa propia se asocia a un lugar de bienestar y de identificación ${ }^{54}$. A pesar de que en las entrevistas realizadas se han encontrado casos que demuestran que la casa familiar también puede ser un lugar de apoyo, demostrando que el hogar familiar no tiene porque ser siempre un lugar homofóbico ${ }^{55}$, en la mayoría de casos sí que se concibe el hogar como un espacio de conflicto para jóvenes no heterosexuales:

Tina: Jo no puc [mostrar la meva sexualitat a l'espai públic]. Perquè els meus pares no ho saben i estic molt reprimida per això. Se'n van enterar fa un any i mig però jo els hi he dit que no, que no, i ara no ho saben. Bueno, jo estic amb ella [senyalant la Edurne, la seva nòvia]. I com ho sàpiguen em moro, perquè m'han reprimir molt. Perquè tenen la mentalitat de Colòmbia i és horrible, la mentalitat. [...] Si no em deixaven sortir de casa... Em vaig quedar a casa, em vaig aprimar com tres quilos en una setmana i poc a poc...

\footnotetext{
${ }^{51}$ Kawale, 2004; Valentine, 1993

${ }^{52}$ Bell y Valentine, 1995; Bell et al., 1994; Binnie, 1997, Valentine, 1993

53 Valentine et al., 2003

${ }^{54}$ ver Elwood, 2000; Kentlyn, 2008; Gorman-Murray, 2007

${ }^{55}$ Gorman-Murray, 2008
} 


\begin{abstract}
Ainhoa: Jo ho veig diferent. El barri és un rollo diferent que Manresa. No sé, jo el meu barri, hi ha certes coses que... Mostrar-me amb ella en públic així i tal no, però... La gent, jo sé que provocaria comentaris... I no per mi, però per la meva família. Per respecte. Per no crear mal ambient per no crear...
\end{abstract}

Andrés: Es que sobretodo mi familia... en Suramérica la mentalidad es mucho más cerrada en este aspecto y el hecho de cogernos de la mano me hacía sentir incómodo...

Estos ejemplos muestran como el hogar familiar es un espacio de malestar, y las restricciones que sufren en él se extienden al espacio público. La cita de Tina muestra como la separación entre lo público y lo privado es ambigua, ya que si ella fuera vista con su pareja en la calle por sus familiares (o alguna persona que pudiera informarles) sufriría igualmente la represión en el espacio doméstico. La homofobia que sufre en su casa se extiende al espacio público impidiendo que pueda mostrarse como lesbiana en él y deba ocultar siempre la relación con su pareja. En este caso, la dependencia hacia su familia la obliga a mantener esta situación, como ella afirma:

Tina: Si tens la seva vida pròpia ja és diferent, perquè quan ja estàs tu independitzada $i$ tens tu el teu allò és molt més diferent, perquè no has de viure cada dia amb la mentida a sobre, saps? I ha de ser diferent, sí o sí.

Como muestra en su cita, su clase social y la opinión de su familia condiciona su situación, ya que las limitaciones para su emancipación son fundamentalmente económicas. A este factor también le añade su origen colombiano, ya que atribuye la mentalidad homofóbica a cuestiones culturales, sintiendo compasión hacia ellos, aumentando su sentimiento de culpa y limitando sus posibilidades de negociación. El hecho de tener que estar permanentemente en situación de alerta por si es vista por alguien condiciona no solo el uso que hace del espacio público sino que marca cómo se siente en los lugares donde va. Y la relevancia del espacio privado también puede verse en el caso contrario. Por ejemplo, la familia de Carla, una chica lesbiana de 17 años, la apoya en todo momento y su hogar supone un lugar de bienestar y reconocimiento, según ella asegura. Esto no significa que no sufra discriminaciones en el espacio público, pero su actitud frente a las posibles agresiones difiere al saber que puede contar con el apoyo familiar. Otra situación que muestra la importancia del espacio privado es cuando éste no aporta la privacidad que se le supone:

\footnotetext{
Ainhoa: Jo espai privat... Jo ni a casa meva tinc espai privat, saps? Perquè és un pis petit, som el meu pare, me mare $i$ el meu germà petit $i$ jo i ella $i$ és un pis de... setanta metres quadrats. I privacitat, poca $i$ si el nen no entra cada dos per tres...
}

Esta cita demuestra como el derecho a la ciudad no puede ir separado del derecho al bienestar en el espacio privado. Según argumenta Fenster, esta división se ha usado históricamente para justificar la subordinación y la exclusión de las mujeres ${ }^{56}$. El caso de Tina, como el de Fátima también evidenciaba, muestran como los derechos y discriminaciones que se sufren en el espacio privado son permeables al espacio público. La homofobia que sufre Tina en su casa familiar, la restricción de los movimientos y las imposiciones espaciales que sufre Fátima por parte de su marido en su casa o los conflictos familiares en casa de Alba muestra como el acceso al espacio público debe ser entendido en relación a la situación que se vive en el espacio privado. La separación entre espacio público y privado entendida como una separación física y rígida pierde

\footnotetext{
${ }^{56}$ Fenster, 2005
} 
sentido, pero a la vez refuerza la idea de que la concepción de espacio público se ha fundamentado sobre una concepción de lo privado como lo no político.

\section{Conclusiones}

Como se ha mostrado, el acceso de la juventud al espacio público está determinado por la posición que ocupa en diversas estructuras de poder como el género, la sexualidad, la etnia o la clase social. Entendiendo el acceso no solo como la presencia en la calle sino también como un bienestar en ella, gran parte de las personas entrevistadas mostró sentirse incómoda por alguna dimensión de su identidad. Paralelamente, también se demuestra la relevancia que el espacio público tiene en sus vidas cotidianas y su capacidad de gestionar sus identidades y los espacios que usan para sentirse bien.

El miedo, el control por parte de la comunidad y la heteronormatividad en la calle aparecen como los tres grandes factores que determinan la experiencia. Si bien el miedo tiene como componente más relevante el género, se ha mostrado como éste está siempre constituido por otras identidades. Las posibilidades que permite una determinada clase social o la etnicidad son factores que alivian o intensifican la percepción del miedo, y las negociaciones entre estas identidades son factores que muestran su dinamismo y su variación según los espacios. Por otro lado, el control social que ejerce la propia comunidad aparece como un factor determinante de los usos en el espacio público. No es solamente el hecho de no poder estar en la calle sino la forma como el control sobre los cuerpos se ejerce a través de la mirada. La forma de vestir, de comportarse o las relaciones que se establecen son controladas en un espacio público que funciona como un panóptico. Y la propia comunidad no debe ser solamente entendida como la comunidad de las personas migradas. La cultura heterosexista y heteronormativa es también propia de la 'comunidad' de las chicas blancas manresanas y ciertos comportamientos están sujetos a la represión. Como se ha visto, el acceso al espacio público, entendido también como la posibilidad de expresarse, está restringido para gays y lesbianas que sienten su propia ciudad como un lugar de control, riesgo y no aceptación de su condición sexual.

De esta forma, el análisis espacial de la experiencia muestra como el acceso al espacio público, el derecho a la ciudad, está limitado para gran parte de la población joven, entendida en su complejidad de identidades y prácticas espaciales. Sin ninguna pretensión de hacer extrapolables las evidencias específicas, el análisis interseccional pone de relieve que el estudio de los grupos sociales debe tener en cuenta que la experiencia de la opresión y del privilegio es siempre simultanea y que el estudio de la dinámicas espaciales debe tener en cuenta este factor si quiere evitar exclusiones, la homogenización y el uso de falsos neutros que lleven a conclusiones parciales. Seguramente otras entrevistas a otras jóvenes habrían mostrado intersecciones diferentes, pero lo que se pretende mostrar es que la gente joven no es solo joven, y en el qué más es, se encuentran vectores que, junto con la edad, restringen de formas muy diversas y en diferentes grados el derecho a la ciudad de la juventud. 
Si el derecho a la ciudad, tal y como lo concibió Lefebvre ${ }^{57}$, se basaba en el derecho a la apropiación y a la participación ${ }^{58}$ y si este derecho es un derecho de ciudadanía fundamental, las relaciones que se establecen en el espacio privado deben ser tenidas en cuenta, como también las relaciones patriarcales, racistas, edatistas, capitalistas y heteronormativas que sitúan a los sujetos en posiciones desiguales. Fenster ${ }^{59}$ afirma que las relaciones de género, en relación con otras formas de opresión, limitan el acceso a la ciudad de las mujeres y argumenta que el hecho de aislar la discusión sobre el derecho a la ciudad del derecho al hogar crea una esfera pública neutral esterilizada de las relaciones de poder. La perspectiva interseccional no solo ayuda a tener en cuenta las relaciones de poder sino que también ayuda a comprender el acceso al espacio público como algo experienciado e intrínsecamente parte de la relación entre las dos esferas y entre diferentes formas de subordinación. Y si el derecho a la ciudad es un derecho básico de ciudadanía, la exclusión de una parte importante de la población muestra como el mismo concepto de ciudadanía se fundamenta sobre exclusiones.

\section{Bibliografía}

BAYLINA, Mireia; ORTIZ, Anna; PRATS, Maria. Children and playgrounds in Mediterranean cities. Childrens Geographies, 2006, 4(2), p. 173-183.

BELL, D. and VALENTINE, G. (editors). Mapping desire: geographies of sexualities. London: Routledge, 1995.

BELL, D., BINNIE, J., CREAM, J. y VALENTINE, G. All hyped up and no place to go. Gender, Place and Culture, 1994, 1, p. 31-47.

BINNIE, J. Coming out of geography: towards a queer epistemology? Environment and Planning D: Society and Space, 1997, 15, p. 223-37.

BROWN, M. Gender and Sexuality I: Intersectional anxieties. Progress in Human Geography, 2011, 36(4), p. 541-550.

CAHILL, C. Street Literacy: Urban Teenagers Strategies for Negotiating their Neighbourhood. Journal of Youth Studies, 2000, 3: 3, p. 251- 277

CHATTERTON, Paul y HOLLANDS, Robert. Theorising Urban Playscapes: Producing, Regulating and Consuming Youthful Nightlife City Spaces. Urban Studies, 2002, 39, p. 95-116.

CHIU, Chihsin. Contestation and Conformity: street and Park Skateboarding in New York City Public Space. Space and Culture, 2009, 12, p. 25-42.

COLLINS, Damian. C.A y KEARNS, Robin A. Under curfew and under siege? Legal geographies of young people. Geoforum, 2001, 32, p. 389-403

\footnotetext{
${ }^{57}$ Lefebvre, 1968

${ }^{58}$ Purcell, 2002

${ }^{59}$ Fenster, 2005
} 
CRENSHAW, K. Mapping the Margins: Intersectionality, Identity Politics, and Violence against Women of Colour. Stanford Law Review, 1991, 43, p. 1241-1299.

CUCURELLA, Ariadna. La perspectiva de gènere en el disseny i lús despais públics urbans : el cas del Parc dels Colors de Mollet del Vallès (Barcelona). Documents dAnàlisi Geogràfica, 2007, 49, p. 119-138.

Documents dAnàlisi Geogràfica (DAG). Geografies de la infància, la joventut i les famílies, 2011, 57(1), Universitat Autònoma de Barcelona i Universitat de Girona, 191.

DRISKELL, David y FOX, Carly and KUDVA, Neema. Growing up in the new New York: youth space, citizenship, and community change en hyperglobal city. Environment and Planning A, 2008, 40, p. 2831-2844.

ELWOOD, S.A. Lesbian Living spaces: Multiple Meanings of home. Journal of Lesbian Studies, 2000, vol. 4, Num 1, p. 11-27.

EHRKAMP, Patricia. Risking publicity: masculinities and the racialization of public neighborhood space. Social \& Cultural Geography, 2008, 9 (2), p. 117-133.

EHRKAMP, Patricia. Ive had it with them! Younger migrant womens spatial practices of conformity and resistance. Gender, Place and Culture, 2013, 20(1), p. 19-36.

EVANS, R. Negotiating social identities: The influence of gender, age and ethnicity on young peoples street careers in Tanzania. Childrens Geographies, 2006, 4: 1, p. 109128.

FENSTER, Tovi. The right to the gendered city: different formations of belonging in everyday life. Journal of Gender Studies, 2005, Vol. 14, No. 3, p. 217-231.

FERNÁNDEZ-SALINAS, Víctor. Visibilidad y escena gay masculina en la ciudad española, Documents dAnàlisi Geogràfica, 2007, 49, p. 139-160.

FREIXANET-MATEO, M. (coord.). No surtis sola. Espais píblics segurs amb perspectiva de gènere. Barcelona: Institut de Ciències Polítiques i Socials, 2011.

GARCIA RAMON, M.D.; ORTIZ, A.; PRATS, M. Espacios Públicos, Género y diversidad: Geografías para unas ciudades inclusivas. Barcelona: Icaria Editorial, 2014.

GORMAN-MURRAY, A. Contesting domestic ideals: queering the Australian home. Australian Geographer, 2007a, 38, p. 195-213.

GORMAN-MURRAY, A. Reconciling self: gay men and lesbians using domestic materiality for identity management. Social \& Cultural Geography, 2008, 9:3, p. 283301.

GOUGH, Katherine V. and FRANCH, Monica. Spaces of the street: Socio-spatial mobility and exclusion of youth in Recife. Childrens Geographies, 2005, 3: 2, p. 149166. 
HOPKINS, P. Young people, place and identity. Nova York: Routledge, 2010.

HOPKINS, P and Pain, R. Geographies of age: thinking relationally. Area, 2007, 39.3, p. 287-294.

HOOKS, B. Feminist theory: From margin to center. Boston: South End, 1984.

HOOKS, B. Yearning: Race, Gender, and Cultural Politics. Boston: South End Press, 1990.

HYAMS, Melissa. Adolescent Latina Bodyspaces: Making Homegirls, Homebodies and Homeplaces. Antipode, 2003, 35, p. 535- 558.

KAWALE, R. Inequalities of the heart: the performance of emotion work by lesbian and bisexual women in London, England, Social \& Cultural Geography, 2004, 5:4, p. 565-581.

KATZ, Cindi. Los terrores de la hipervigilancia : seguridad y nuevas espacialidades de la niñez, Documents dAnàlisi Geogràfica, 2006, 47, p. 15-29.

KENTLYN, S. The Radically Subversive Space of the Queer Home: Safety Houseand Neighbourhood Watch. Australian Geographer, 2008, 39: 3, p. 327-337.

KONING, Anouk de. Gender, Public Space and Social Segregation in Cairo: Of Taxi Drivers, Prostitutes and Professional Women, Antipode, 2009, 41 (3), p. 533-556.

KOSKELA, H. Bold walk and breakings: Womens spatial confidence versus fear of violence. Gender Place and Culture, 1997, 4(3), p. 301-314.

LEFEBVRE, H. Le droit à la ville. Paris: Anthropos, 1968.

LIESHOUT, Maartje van and Aarts, Noelle. Youth and Immigrants Perspectives on Public Space. Space and Culture, 2008, 11, p. 497-513.

MCDOWELL, L. Thinking through work: complex inequalities, constructions of difference and trans-national migrants. Progress in Human Geography, 2008, 32(4), p. 491-507.

NOFRE, Jordi. Lagenda cultural oculta. Una deconstruccio de loci nocturn de Barcelona $i$ els seus suburbis. Tesis Doctoral. Barcelona: Universitat de Barcelona, 2008.

NOLAN, Nicholas. The ins and outs of skateboarding and transgression in public space in Newcastle, Australia. Australian Geographer, 2003, 34 (3), p. 311-327.

ONEIL, Mary Lou. Youth Curfews in the United States: The Creation of Public Spheres for Some Young People. Journal of Youth Studies, 2002, 5 (1), p. 49-67.

ORTIZ, Anna. Ús i apropiació de la Via Júlia i la rambla del Raval de Barcelona des duna perspectiva de gènere, Documents dAnàlisi Geogràfica, 2004, 44, p. 89-108. 
ORTIZ, Anna. Geografías de la infancia: descubriendo «nuevas formas» de ver y de entender el mundo, Documents dAnàlisi Geogràfica, 2007, 49, p. 197-216.

ORTIZ, Anna; PRATS Ferret, Maria; BAYLINA, Mireia. Métodos visuales y geografías de la infancia: dibujando el entorno cotidiano". Scripta Nova. Revista electrónica de Geografía y Ciencias Sociales, 2012, XVI.

PAIN, R. Gender, Race, Age and Fear in the City. Urban Studies, 2001, 38, p. 899-913.

PLATERO, L. (ed). Intersecciones: cuerpos y sexualidades en la encrucijada. Barcelona: Edicions Bellaterra, 2012.

PRATS, Maria; BAYLINA, Mireia; ORTIZ, Anna. Los lugares de la Amistad y la vida cotidiana de chicas y chicos adolescentes en un barrio de Barcelona. Revista LatinoAmericana de Geografia e Gênero, 2012, Ponta Grossa, 3(2), p. 116-124.

PURCELL, M. Excavating Lefevbre: The right to the city and its urban politics of the inhabitant. GeoJournal, 2002, 58, p. 99-108.

RODÓ-DE-ZÁRATE, Maria. El jovent i els espais públics urbans des de la perspectiva de gènere: Un estat de la qüiestió des de la geografia. Documents dAnàlisi Geogràfica, 2011, vol. 57/1, p. 147-162.

RODÓ-DE-ZÁRATE, M. Developing Geographies of Intersectionality with Relief Maps: reflections from youth research in Manresa, Catalonia. Gender, Place and Culture, 2014, vol 21/8, p. 925-944.

RODÓ-DE-ZÁRATE, Maria and BAYLINA, Mireia. Learning in/through public space: young girls and feminist consciousness-raising. In Mills, S. and Kraftl, P. (eds.). Informal Education, Childhood and Youth: Geographies, Histories, Practices. Basingstoke: Palgrave Macmillan, 2014.

ROSE, G. Feminism \& geography. Cambridge: Polity Press, 1993.

RUDDICK, S. Constructing difference in public spaces: Race, class, and gender as interlocking systems. Urban Geography, 1996, 17, p. 132-51.

SERRA, Anna. Vida quotidiana en un espai urbà transformat: El Mercadal de Girona des duna perspectiva de gènere. Documents dAnàlisi Geogràfica, 2007, 49, p. 161-180.

SKELTON, Tracey y GOUGH, Katherine V. Introduction: Young Peoples Im/Mobile Urban Geographies. Urban Studies, 2013, 50, p. 455-466.

TAYLOR, Yvette and ADDISON, Michelle. (Re)constituting the past, (re)branding the present and (re)imagining the future: womens spatial negotiation of gender and class, Journal of Youth Studies, 2009, 12: 5, p. 563-578.

THOMAS, M.E. Girls, consumption space and the contradictions of hanging out in the city. Social \& Cultural Geography, 2005, 6: 4, p. 587-605. 
TRAVLOU, Penny, OWENS, Patsy Eubanks, THOMPSON, Catharine Ward y MAXWELL, Lorraine. Place mapping with teenagers: locating their territories and documenting their experience of the public realm. Childrens Geographies, 2008, 6 (3), p. $309-326$

TRILLA, J. (coord.). Jóvenes y espacio público. Del estigma a la indiganción. Barcelona: Ed. Bellaterra, 2011.

VALENTINE, G. Images of danger: womens sources of information about the spatial distribution of male violence, Area, 1992, 24, p. 22-29.

VALENTINE, G. (Hetero)sexing space: lesbian perceptions and experiences of everyday spaces. Environment and Planning D: Society and Space, 1993, 11 (4), p. 395413.

VALENTINE, G. Exploring children and young peoples narratives of identity. Geoforum, 2000, 31, p. 257-267.

VALENTINE, G. Theorizing and Researching Intersectionality: Challenge for Feminist Geography, Professional Geographer, 2007, 59:1, p. 10-21.

VALENTINE, G. y SKELTON, Tracey. Finding oneself, Losing oneself: The Lesbian and Gay Scene as a Paradoxical Space. International Journal of Urban and Regional Research, 2003, Vol 27.4 p. 849-66.

WOOLLEY, Helen. Freedom of the city: Contemporary issues and policy influences on children and young peoples use of public open space in England. Childrens Geographies, 2006, 4 (1), p. 45-59.

(c) Copyright Maria Rodó de Zárate, 2015.

(C) Copyright Scripta Nova, 2015.

Ficha bibliográfica:

RODÓ DE ZÁRATE, Maria. El acceso de la juventud al espacio público en Manresa. Una aproximación desde las geografías feministas de la interseccionalidad. Scripta Nova. Revista Electrónica de Geografía y Ciencias Sociales. [En línea]. Barcelona: Universidad de Barcelona, 1 de marzo de 2015, vol. XIX, no 504. <http://www.ub.es/geocrit/sn/sn-504.pdf>. ISSN: 11389788. 